\section{$>$ BITÁCORA DE CAMPO}

\section{Croquis de viaje a Chiloé} MARCELO ANÍBAL VARGAS CORNEJO

$>$ Arquitecto. Espiral producciones ORCID 0000-0002-6978-3352

DOI 10.22370/margenes.2021.14.21.3106

La universidad había sido dura pero colorida. Se venía por fin el tan anhelado viaje al archipiélago de Chiloé. Reencontrarme con las líneas y formas que me cautivaron en un comienzo para tomar este camino y darle un sentido práctico al quehacer de la observación. Papel verjurado 90; una delicia que me demandaba de manera compulsiva el dibujar. Volver a enamorarme del papel y la tinta era el enunciado perfecto para esta travesía.

Junto con la cultura, el gran valor de este territorio es el paisaje. Un paisaje imaginario delineado por un borde mar que ha sido testigo del impetuoso intento del ser humano por subsistir. Labor y obra ligada al territorio. Territorio marítimo austral, el cual al sumergirnos en sus rincones, voy relacionando las cualidades geográficas y naturales de la isla con el poco conocimiento hasta ese minuto de sus primeros habitantes.

En un comienzo, los Chonos eran los que habitaban por estas latitudes, los cuales construyeron sus dalcas con madera de alerces, habitando dentro de ellas.

Por otra parte, los Huilliches, pueblo sedentario, que a la llegada a la isla, se sincretizan sus culturas y se van generando nuevos medios de organización cultural, principalmente extractivas. Sincretismo que fue gestando este evitar mixto entre el posicionamiento de la tierra versus sus libres desplazamientos por el mar, ahora en lanchas.

Observo que no intentaron inventar la pólvora en la isla, buscando el camino propio, sino que generaron un desarrollo de su cultura dialogando desde sus bases con lo preexistente.

La disponibilidad de madera es la que permite la expansión y desarrollo de su cultura y vida. Clima, patrimonio e identidad. Obra no desarraigada del lugar. Arquitectura ligada al territorio. Conocimiento acabado de las materias primas disponibles, principalmente madera, reconociendo sus especies y distintos usos es lo que permite de manera orgánica, generando una producción sustentable de hábitat. El hombre ha reconocido los materiales más apropiados para la construcción de sus viviendas. Materiales y tradiciones fundidos por las condiciones históricas. El lugar se construyó a sí mismo basándose en la tradición para ser parte de la cultura, manifestando la voluntad comunitaria de mantener lo divino desde la naturaleza, e ir a la arquitectura para dar lugar al hombre y permitir su humanización.

\section{Vida insular contenida en un mar interior}

Comienza a envejecer la población, razón por la cual aparece la casa de zinc obtenida de puertos y astilleros cercanos. Materialidad por la cual se ve a manifiesto que la capacidad de autoconstrucción se mantiene intacta; el ingenio sigue activo. Lo que hay en el medio, se utiliza para darle el fin necesario, independiente de los cambios de materialidad. En Chiloé no existían arquitectos. Maestro mayor, los entendidos, portadores de los conocimientos y técnicas constructivas ancestrales, encargados de reproducir todas las obras de arquitectura pertinente al lugar, manteniendo la condición finita de las obras.
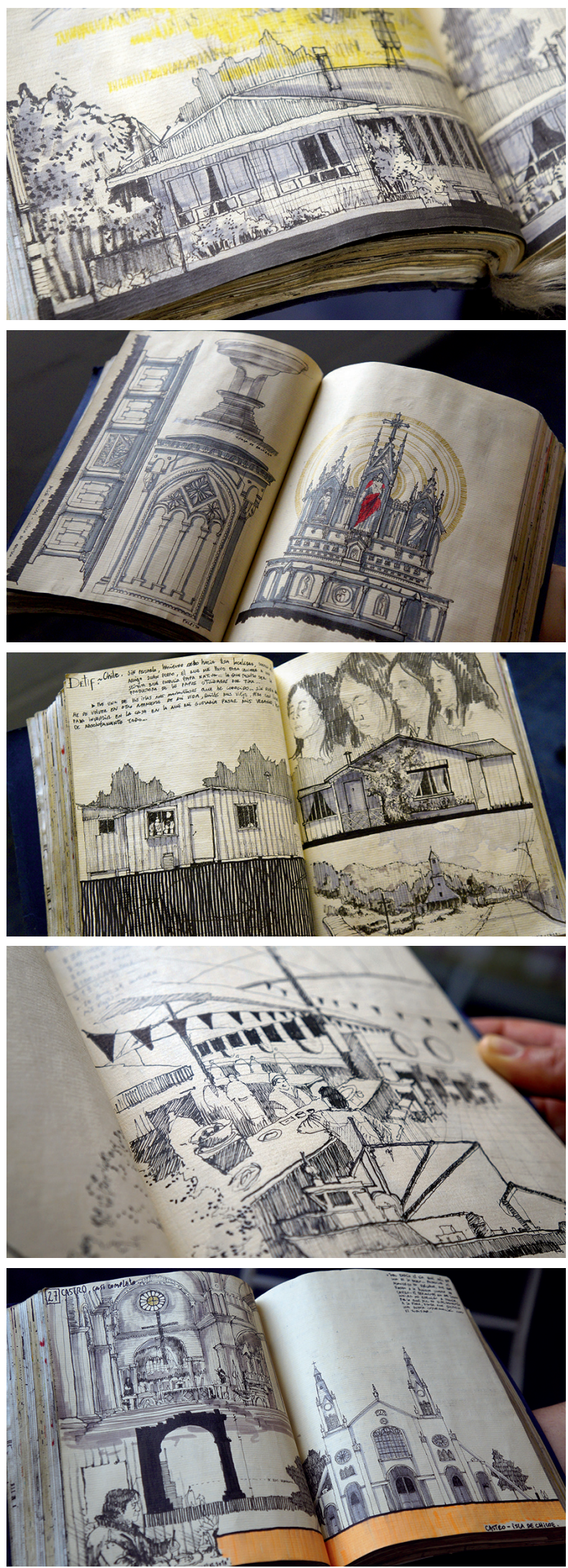

Cultura de la madera se regenera a sí misma desde los vestigios del habitar pasado

La vida parece muy precaria, pero coexiste con su entorno resistiendo los embates de trabajar en el mar. La identidad se transforma. La creatividad de los carpinteros en contacto estrecho con las posibilidades constructivas de su entorno le proporciona y reconociendo la variabilidad del reciclaje material. 


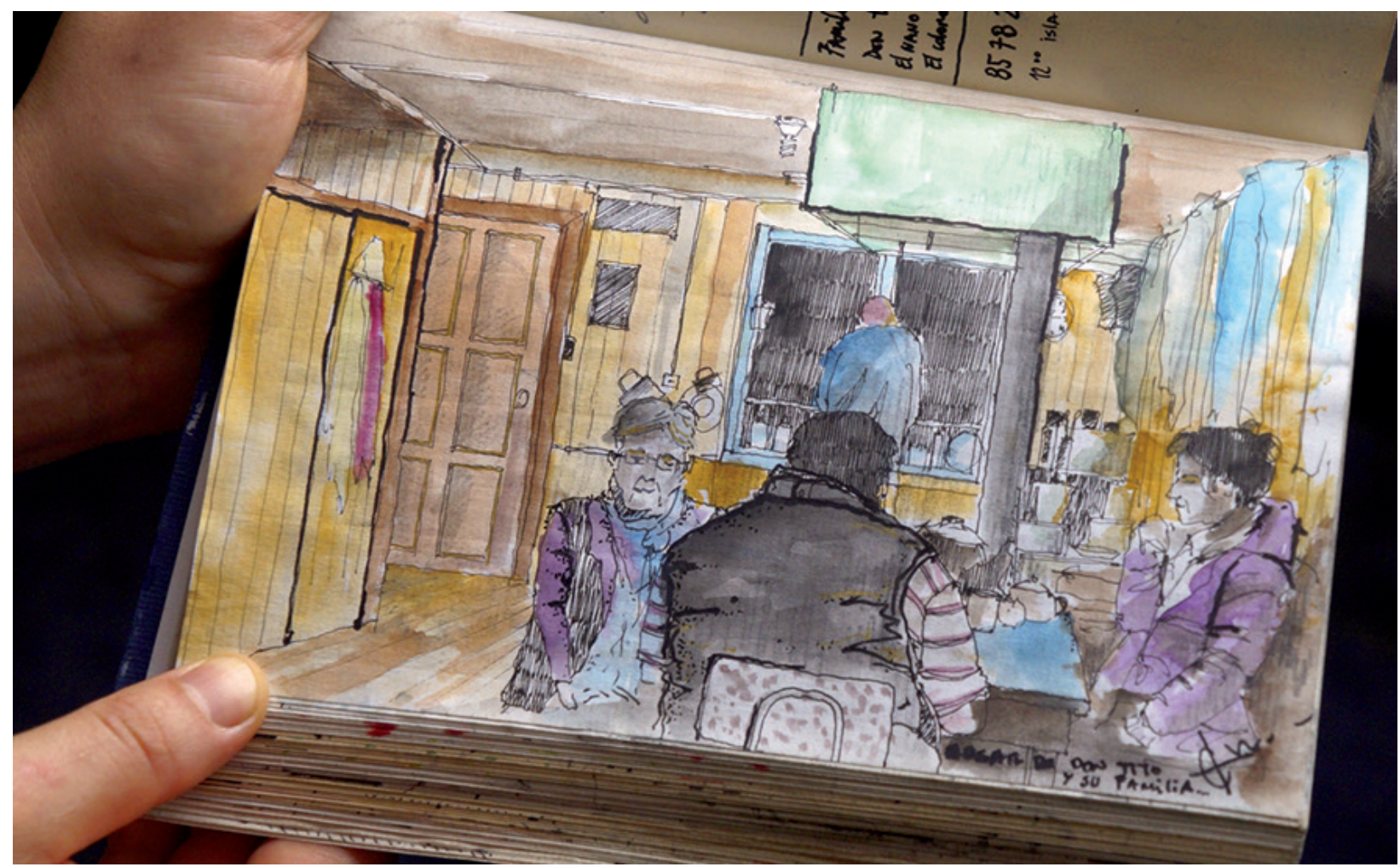

Parece ser que aquí cambian las reglas del mundo... lo efímero se acepta y se reconoce como hábitat, en medio la naturaleza como la directriz del habitar humano.

Una tierra sin arquitectos, sin necesitarlos; esculpió su habitar desde la tierra misma.

\section{Hotel Tierra, Chiloé}

Como muchas veces mi padre me habló, no me falló. Personalmente pienso que mi retorno a este lugar debe ser pronto, ya que dejé mucho por dibujar, recorrer y merodear.

Detif. Sin pensarlo, haciendo dedo hacia esta localidad, conocí al amigo Juan Pedro, el que me llevo al rincón final de la isla Lemuy para conocer a una de las productoras de papas nativas más emblemática de la zona.

Fue una de las islas más maravillosas que he conocido. Sin duda he de volver en otro momento de mi vida, quizás más viejo.

Chullek, representado por la familia de esfuerzo, todos sus hijos han sido criados para el cuidado del campo. Don Tito y doña Argelina, junto a Nano, Javier y Francisca han sido muy atentos conmigo.

En este lugar el trabajo es muy bien valorado, y todo lo que pueda ser retribuido con labores de campo será agradecido y recompensado.

Aprendí labores como el realizar tortillas de rescoldo, elaborar la chicha de manzana más deliciosa de la isla, y a su vez, alimentar al ganado, ovejas y aves del campo.

Un día nos llevaron a mariscar a la playa de Matao, donde nos esperaba una baja de marea realmente impactante. Recolectar mariscos es como cosechar papas del campo.

Jamás había experimentado una conexión tan rica con la tierra.
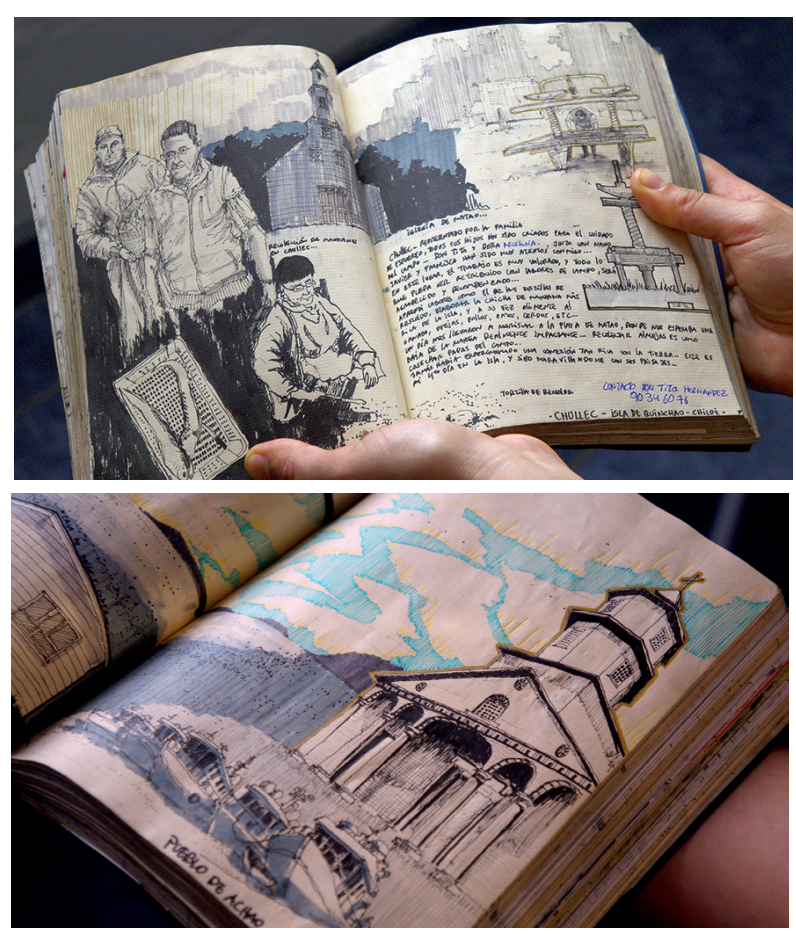